\title{
Pengaruh Air Kelapa dan BAP terhadap Tanaman Teh Klon GMB 7 setelah Centering Ke-2
}

\section{SYLVIA PUSPA HARJANTI ${ }^{*}$, SANTI ROSNIAWATY, MIRA ARIYANTI, DAN YUDITHIA MAXISELLY}

\author{
Jurusan Agroteknologi, Fakultas Pertanian, Universitas Padjadjaran \\ Jl. Raya Bandung-Sumedang Km. 21, Jatinangor \\ ${ }^{*}$ E-mail: sylviapuspa97@gmail.com
}

\begin{abstract}
The Effect of Coconut Water and Bap on Tea Plant Clone Gmb 7 After $2^{\text {nd }}$ Centering. Tea plants as one of the leading commodities in Indonesia demanding high productivity. Clone GMB 7 and maintenance such as the formation of the area of plucking by $1^{\text {st }}$ centering and $2^{\text {nd }}$ centering on the immature plant can be done to improve the productivity of tea. Centering that plays a role in stimulating bud formation can be enhanced by the addition of Plant Growth Regulator (PGR) derived from natural ingredients such as coconut water and synthetic ingredients such as Benzyl Amino Purine (BAP). This research was conducted to determine the effect of BAP concentration and coconut water on tea plants after the $2^{\text {nd }}$ centering. The research was conducted from July 2017 to September 2017 at Ciparanje Field Station, Padjadjaran University. The experimental design used was Randomized Block Design with 7 treatments repeated 4 times. The treatment used were: control (without PGR); $25 \%$ coconut water; $50 \%$ coconut water; $75 \%$ coconut water; 60 ppm BAP; 90 ppm BAP; and $120 \mathrm{ppm}$ BAP. The best result are shown by $50 \%$ coconut water on the ratio of leaves number, the ratio of bud number, and the bud length.
\end{abstract}

Keywords: second centering, benzyl amino purine, coconut water

\section{PENDAHULUAN}

Tanaman teh (Camellia sinensis (L.) O. Kuntze) termasuk kedalam salah satu komoditas ekspor utama dari sektor perkebunan. Kondisi tersebut membuat permintaan akan teh menjadi besar, namun keadaan tersebut tidak didukung oleh produktivitas teh di Indonesia. Hal tersebut didukung oleh data statistik teh Indonesia tahun 2014, bahwa telah terjadi penurunan luas area perkebunan teh dari tahun 2010 hingga 2014. Penurunan pada tahun 2014 terjadi sebesar 0,93\% dari tahun 2013, diikuti dengan berkurangnya produksi teh sebesar 2,19\%. Hal tersebut mengakibatkan penurunan nilai ekspor dari 70,824 ton menjadi 66,399 ton (Hardjo, 2014).

Berbagai cara dapat dilakukan untuk meningkatkan produksi teh di Indonesia, salah satunya melalui kultur teknis. Penggunaan klon unggul merupakan salah satu kultur teknis yang awal untuk mendapatkan produksi tinggi di kemudian hari (Haq dan Karyudi, 2013). Pusat 
SYLVIA PUSPA HARJANTI. et al. Pengaruh Air Kelapa dan BAP terhadap Tanaman Teh KIon...

penelitian teh dan kina telah merilis beberapa klon unggul, diantaranya adalah klon unggul seri Gambung yang diberi nama klon GMB 1, GMB 2, GMB 3, GMB 4, GMB 5, GMB 6, GMB 7, GMB 8, GMB 9, GMB 10, dan GMB11. Klon GMB 7 merupakan klon dengan potensi produksi yang paling tinggi yaitu $5.800 \mathrm{~kg} / \mathrm{ha} / \mathrm{tahun}$.

Penggunaan klon unggul harus diiringi dengan kegiatan kultur teknis lainnya agar mendapat hasil yang maksimal, seperti proses pemeliharaan. Sebelum dapat menghasilkan, tanam teh akan melalui fase Tanaman Belum Menghasilkan (TBM), dimana fase ini akan sangat berpengaruh terhadap tanaman teh di kemudian hari. Salah satu proses pemeliharaan TBM teh yang penting adalah pembentukan bidang petik, salah satunya melalui centering. Centering dilakukan sebanyak dua kali, dengan tujuan merangsang pembentukan tunas dalam bidang petik.

Terbentuknya tunas melalui centering dapat terjadi karena hilangnya sintesis auksin pada meristem apikal akibat pemenggalan. Hal tersebut mengakibatkan terjadinya peningkatan hormon sitokinin pada ketiak daun, yang mengakibatkan terjadinya pembelahan sel dan diferensiasi jaringan pengangkut tunas lateral sehingga membetuk tunas (Darmanti et al., 2008).

Centering ke-1 dilakukan dengan memotong batang tanaman teh pada ketinggian $15-20 \mathrm{~cm}$ (dari permukaan tanah) dan memiliki 5 helai daun. Centering ke-2 dilakukan saat umur 6-9 bulan di lapangan, atau ketika ketinggian cabang baru sekitar $50-60 \mathrm{~cm}$, dengan cara memenggal cabang pada ketinggian $30 \mathrm{~cm}$.
Proses pembentukkan tunas pada tanaman teh setelah centering ke-2 dapat ditingkatkan melalui pemberian Zat Pengatur Tumbuh (ZPT) sitokinin dari luar tanaman (eksogen). Zat Pengatur Tumbuh yang digunakan dapat berupa ZPT sintetik seperti Benzil Amino Purin (BAP) maupun ZPT alami seperti sir kelapa. Benzil Amino Purin merupakan salah satu sumber ZPT sitokinin yang cukup umum digunakan untuk merangsang penunasan (Lestari et al., 2013). Air kelapa merupakan salah satu sumber fitohormon alami yang cukup mudah didapatkan, dimana salah kandungan hormonnya adalah sitokinin (Yong et al., 2009).

Pemberian hormon eksogen terkadang diperlukan untuk memenuhi kebutuhan hormon tanaman agar mendapat pertumbuhan yang optimum (Leovici dkk., 2014). Pemberian ZPT dapat memberikan dampak yang positif pada pertumbuhan tanaman ketika diberikan dalam konsentrasi yang rendah (Fahmi, 2016). Kebutuhan ZPT akan berbeda - beda untuk setiap tanaman, tergantung pada jenis, lingkungan, fase tanaman, dan faktor-faktor lainnya. Hal tersebut menjelaskan bahwa diperlukan suatu penelitian untuk mengetahui kesesuaian antara konsentrasi dan ZPT yang digunakan, dalam hal ini berupa BAP dan air kelapa pada tanaman teh setelah centering ke-2.

\section{BAHAN DAN METODE}

Percobaan dilaksanakan di kebun percobaan Ciparanje milik Fakultas Pertanian Universitas Padjadjaran, Jatinangor kabupaten Sumedang. Bahan yang digunakan selama percobaan adalah tanaman teh klon GMB 7 berumur 1 tahun 6 bulan sebanyak 
56 tanaman, yang sebelumnya telah dilakukan centering ke-1, air kelapa, aquades, Benzil Amino Purin (BAP), dan alkohol $70 \%$.

Percobaan ini menggunakan metode analisis percobaan berupa Rancangan Acak Kelompok (RAK) sederhana dengan 7 perlakuan (setiap perlakuan terdiri dari 2 tanaman) yang diulang sebanyak 4 kali. Adapun ketujuh perlakuan yang digunakan adalah A (kontrol/tanpa pemberian ZPT); B (25\% air kelapa); C (50\% air kelapa); D (75\% air kelapa); E (60 ppm BAP); F (90 ppm BAP); dan G (120 ppm BAP). Hasil analisis dimuat dalam tabel Analisis of Varians pada taraf 5\%, apabila didapati hasil yang berbeda nyata maka diuji lanjut menggunakan Duncan pada taraf 5\%.

Pemberian perlakuan diberikan setelah dilakukan centering ke-2. Centering ke-2 dilaksanakan sekitar 6 - 9 bulan setelah centering ke-1 atau cabang baru memiliki tinggi $50-60 \mathrm{~cm}$, dengan memotong cabang baru tersebut pada ketinggian $30 \mathrm{~cm}$ (Wibowo, 1997). Tanaman yang telah dilakukan centering ke-2 diberi perlakuan berupa air kelapa $25 \%$, air kelapa $50 \%$, air kelapa 75\%, BAP 60 ppm, BAP 90 PPM, dan BAP $120 \mathrm{ppm}$, dengan dosis $10 \mathrm{ml}$ per tanaman pada 0 MSP dan 2 MSP, 11,25 ml per tanaman pada 4 MSP dan 6 MSP, dan $12,5 \mathrm{ml}$ per tanaman pada 8 MSP dan 10 MSP. Aplikasi perlakuan dilakukan menggunakan handsprayer pada pagi hari sekitar pukul 08.00 WIB, ketika embun sudah turun dan matahari belum terlalu terik.

Setelah aplikasi perlakuan dilakukan pengamatan terhadap variabel pertumbuhan tanaman berupa pertambahan tinggi tanaman, pertambahan diameter batang, rasio pertambahan dan pengurangan jumlah daun (daun/cabang), rasio pertambahan jumlah tunas (tunas/cabang), pertambahan jumlah cabang, pertambahan panjang tunas $[\mathrm{cm} / 14$ hari setelah perlakuan (HSP)], pertambahan panjang cabang, dan luas daun. Pengamatan dilakukan pada 0 MSP, 2 MSP, 4 MSP, 6 MSP, 8 MSP, 10 MSP, dan 12 MSP terhadap seluruh variabel pengamatan kecuali pada variabel luas daun yang hanya diamati di akhir percobaan yaitu pada 12 MSP.

Pertambahan tinggi tanaman didapatkan dengan mengurangi tinggi batang utama setiap minggu dilakukannya pengamatan dengan tinggi awal batang utama (0 MSP). Pertambahan diameter batang didapatkan dengan mengurangi diameter batang saat pengamatan dengan diameter batang saat 0 MSP. Rasio pertambahan dan pengurangan jumlah daun (daun/cabang) didapatkan dengan mengurangi jumlah daun pada saat pengamatan dengan jumlah daun saat 0 MSP kemudian dibagi dengan jumlah cabang saat 0 MSP. Pertambahan dan pengurangan jumlah daun terjadi karena adanya daun baru yang tumbuh dan daun yang gugur akibat proses recovery tanaman setelah centering ke-2. Daun yang dihitung merupakan daun yang telah membuka sempurna. Rasio pertambahan jumlah tunas (tunas/cabang) didapatkan dengan menjumlahkan seluruh tunas yang terbentuk setelah centering ke-2 dilakukan (0 MSP) hingga waktu pengamatan dilakukan kemudian dikurangi dengan jumlah tunas pada $0 \mathrm{MSP}$, hasilnya dibagi dengan jumlah cabang pada 0 MSP. Tunas yang dihitung merupakan tunas dengan panjang (batang) minimal $1 \mathrm{~cm}$ tanpa pucuk. Pertambahan jumlah cabang didapatkan dengan 
SYLVIA PUSPA HARJANTI. et al. Pengaruh Air Kelapa dan BAP terhadap Tanaman Teh KIon...

menjumlahkan seluruh cabang yang terbentuk setelah 0 MSP hingga waktu pengamatan dilakukan kemudian dikurangi dengan jumlah cabang pada 0 MSP. Pertambahan panjang tunas didapatkan dengan mengurangi panjang tunas saat pengamatan dengan panjang tunas pada waktu pengamatan sebelumnya (2 minggu sebelumnya/14 hari sebelumnya). Perhitungan tersebut dilakukan karena tunas tidak seluruhnya terbentuk pada 0 MSP (terdapat tunas yang baru tumbuh pada pertengahan waktu percobaan). Pertambahan panjang cabang didapatkan dengan mengurangi panjang cabang pada saat pengamatan dengan panjang cabang pada 0 MSP. Perhitungan luas daun dilakukan dengan cara menscan selueruh daun yang membuka sempurna menggunakan alat Leaf Area Meter (luas tiap daun diakumulasi). Perhitungan yang dilakukan dengan cara rasio dilakukan untuk menghindari pengaruh perbedaan jumlah cabang pada awal percobaan sebagai pengaruh dari pemberian perlakuan serupa pada centering ke-1. Jumlah cabang yang berbeda memungkinkan pertambahan jumlah daun dan cabang yang berbeda pula, jumlah cabang yang lebih banyak memungkinkan pertumbuhan jumlah daun yang lebih banyak sehingga menghasilkan data pertambahan jumlah daun dan tunas yang kurang tepat.

\section{HASIL DAN PEMBAHASAN}

Berdasarkan percobaan yang telah dilakukan, pemberian ZPT sitokinin memberikan pengaruh lebih baik terhadap beberapa variabel pertumbuhan tanaman teh dibandingkan dengan kontrol/tanpa pemberian ZPT (perlakuan A). Seluruh variabel pertumbuhan tanaman memiliki peran tersendiri dalam menciptakan tanaman yang tumbuh optimal serta memiliki keterkaitan antara satu variabel dengan variabel lainnya. Salah satu variabel penting yang perlu ditingkatkan pertumbuhannya pada tanaman teh yang belum menghasilkan adalah pembentukan tunas yang kemudian akan menjadi cabang. Hal tersebut berkaitan dengan pembentukan bidang petik tanaman teh sebagai tempat tumbuhnya daun untuk dipanen di kemudian hari.

Hasil percobaan menunjukkan bahwa perlakuan $\mathrm{C}$ berpengaruh nyata lebih baik dibandingkan perlakuan A dalam variabel rasio pertambahan dan pengurangan jumlah daun pada 2 MSP dan $4 \mathrm{MSP}$, rasio pertambahan jumlah tunas pada $8 \mathrm{MSP}$, dan pertambahan panjang tunas pada 8 MSP. Perlakuan $\mathrm{F}$ berpengaruh nyata lebih baik dibandingkan perlakuan A dalam variabel rasio pertambahan dan pengurangan jumlah daun pada 2 MSP. Perlakuan G berpengaruh nyata lebih baik dibandingkan perlakuan A dalam variabel rasio pertambahan jumlah tunas dan pertambahan panjang tunas pada 8 MSP. Perlakuan C berupa pemberian air kelapa $25 \%$ memberikan hasil terbaik dilihat dari pengaruhnya terhadap empat variabel pertumbuhan tanaman dan harga yang lebih ekonomis dibandingkan dengan BAP.

\section{Pertambahan Tinggi Batang Utama}

Hasil percobaan pada variabel pertambahan tinggi batang utama menunjukkan tidak adanya pertambahan tingi tanaman. Dipangkasnya titik tumbuh tanaman teh pada saat centering ke-1, menyebabkan turun dan hilangnya kemampuan tanaman teh untuk tumbuh ke atas. Hal tersebut diakibatkan oleh 
terhambatnya sintesis dan perpindahan auksin ke bagian bawah dan ketiak daun, yang berasal dari meristem apikal (Saefas et al., 2017).

Dilakukannya centering ke-2 juga menyebabkan hilangnya sintesis auksin dan meningkatnya kandungan sitokinin pada tanaman teh (Fahmi, 2016). Peningkatan kadar sitokinin pada tanaman teh dapat merangsang pembelahan sel dan diferensiasi jaringan pengangkut tunas lateral sehingga membentuk tunas (Hendaryono dan Wijayani, 1994). Hal tersebut menyebabkan terhambatnya pertumbuhan tanaman ke arah atas (apikal) dan lebih fokus terhadap pertumbuhan yang bergerak ke arah samping (lateral) (Setyamidjaja, 2000).

\section{Rasio Pertambahan dan Pengurangan Jumlah Daun}

Hasil analisis statistik pada variabel rasio jumlah daun menunjukkan adanya perbedaan yang nyata pada 2 MSP dan 4 MSP (Tabel 1). Data yang berbeda nyata pada 2 MSP kemudaian diuji lanjut menggunakan uji jarak berganda Duncan dan menunjukkan hasil perlakuan $\mathrm{C}$ dan $\mathrm{F}$ memberikan pengaruh nyata yang lebih baik dibandingkan perlakuan A. Uji lanjut juga dilakukan pada data 4 MSP dan menunjukkan bahwa perlakuan $\mathrm{C}$ memberi pengaruh nyata yang lebih baik dibandingkan perlakuan A, B, E, dan G.

Terjadinya pertambahan dan pengurangan jumlah daun disebabkan oleh kombinasi faktor internal dan eksternal tanaman. Faktor internal tanaman yang berpengaruh adalah kondisi recovery pasca centering ke-2 dan kandungan sitokinin pada tanaman (yang berasal dari tanaman itu sendiri maupun yang diberikan melalui perlakuan), sedangkan faktor eksternal tanaman berasal dari lingkungan.

Kondisi tanaman yang sedang melalui tahap recovery pasca dilakukannya centering ke-2 ditambah kondisi lingkungan yang memiliki suhu maksimum harian yang tinggi mencapai $30^{\circ} \mathrm{C}$ menyebabkan gugurnya daun-daun pada tanaman teh. Kondisi tersebut menyebabkan penurunan jumlah daun dari dua minggu sebelumnya (terjadi pengurangan). Kondisi suhu yang tinggi kemudian direkayasa dengan menanam pohon pelindung Gliricidia sepium. Sitokinin yang diberikan pada tanaman teh mampu memperlambat proses penuaan organ tanaman serta mempertahankan daun tanaman teh agar tidak gugur bahkan membentuk daun baru selama proses recovery berlangsung. Kondisi tersebut menyebabkan daun bertahan pada tanaman lebih lama bahkan bertambah jumlahnya (terjadi pertambahan). Hal tersebut selaras dengan pernyataan Leopold (1955) yang dimuat dalam Djamhuri (2011) bahwa pemberian kandungan sitokinin dapat merangsang pembelahan dan pembesaran sel sehingga menjadi lebih aktif, merangsang pembentukkan tunas secara serempak dan menghindari kerontokan dini pada daun.

Pengaruh nyata yang lebih baik pada tanaman dengan perlakuan pemberian sitokinin air kelapa juga didukung oleh adanya kandungan hormon lainnya seperti $\mathrm{Ca}$ yang berperan dalam proses pembentukkan daun. Hal tersebut selaras dengan pernyataan Listiawati dan Mulyani (2010) yang mengatakan bahwa keberadaan beberapa vitamin dan $\mathrm{Ca}$ di dalam air kelapa mampu merangsang pembentukan daun. Penelitian 
SYLVIA PUSPA HARJANTI. et al. Pengaruh Air Kelapa dan BAP terhadap Tanaman Teh Klon...

sebelumnya yang telah dilakukan oleh berupa air kelapa memberikan pengaruh yang Kurniati (2017) terhadap bibit kemiri Sunan menunjukkan bahwa pemberian ZPT alami

nyata terhadap jumlah daun.

Tabel 1. Rataan rasio pertambahan dan pengurangan jumlah daun akibat pemberian zat pengatur tumbuh air kelapa dan BAP pada tanaman teh Klon GMB 7 setelah centering ke-2

\begin{tabular}{|c|c|c|c|c|c|c|}
\hline \multirow[t]{2}{*}{ Perlakuan } & \multicolumn{6}{|c|}{$\begin{array}{l}\text { Rasio Pertambahan dan Pengurangan Jumlah Daun } \\
\text { (daun/cabang) }\end{array}$} \\
\hline & $2 \mathrm{MSP}$ & $4 \mathrm{MSP}$ & $6 \mathrm{MSP}$ & $8 \mathrm{MSP}$ & $10 \mathrm{MSP}$ & $12 \mathrm{MSP}$ \\
\hline A (Kontrol) & $-0,60 \mathrm{a}$ & $-0,36$ a & 0,57 & $-0,30$ & 1,27 & 1,40 \\
\hline B (Air kelapa 25\%) & $-0,15 a b$ & $-0,40 \quad a$ & 1,05 & 2,40 & 4,25 & 4,07 \\
\hline C (Air kelapa 50\%) & $0,26 \mathrm{~b}$ & $0,24 \mathrm{~b}$ & 1,07 & 3,45 & 5,32 & 7,35 \\
\hline D (Air kelapa 75\%) & $-0,14 a b$ & $-0,01 \mathrm{ab}$ & 0,98 & 2,02 & 4,06 & 4,49 \\
\hline $\mathrm{E}(\mathrm{BAP} 60 \mathrm{ppm})$ & $-0,23 \mathrm{ab}$ & $-0,38$ a & 0,54 & 0,60 & 3,13 & 3,84 \\
\hline F (BAP 90 ppm) & $0,27 b$ & $-0,00 \mathrm{ab}$ & 0,27 & $-0,29$ & 4,61 & 5,11 \\
\hline G (BAP 120 ppm) & $-0,18 a b$ & $-0,40 \quad a$ & $-0,02$ & 0,72 & 4,94 & 5,43 \\
\hline
\end{tabular}

Keterangan : 1). MSP = Minggu Setelah Perlakuan.

2). Angka yang tidak diiringi dengan notasi pada kolom yang sama menunjukkan tidak adanya perbedaan nyata pada taraf kepercayaan 5\%.

3). Angka yang diiringi dengan notasi pada kolom yang sama menunjukkan adanya perbedaan nyata pada taraf kepercayaan $5 \%$.

\section{Rasio Pertambahan Jumlah Tunas}

Hasil analisis statistik pada variabel rasio pertambahan jumlah tunas menunjukkan adanya perbedaan yang nyata pada taraf kepercayaan $5 \%$ pada 8 MSP (Tabel 2). Hasil tersebut kemudian diuji lanjut menggunakan uji jarak berganda Duncan yang menunjukkan bahwa perlakuan $\mathrm{C}$ berpengaruh nyata lebih baik terhadap perlakuan A dan F, dan tidak berbeda nyata terhadap perlakuan $\mathrm{B}, \mathrm{D}, \mathrm{E}$, dan $\mathrm{G}$, serta perlakuan $\mathrm{G}$ berpengaruh nyata lebih baik terhadap perlakuan A. Kondisi tersebut kemungkinan disebabkan oleh adanya peningkatan kandungan sitokinin akibat centering ke-2 dan pemberian ZPT sitokinin dari luar. Kondisi ini selaras dengan pernyataan Gardener (1991) dalam Leovici dkk (2014) yang mengatakan bahwa suatu tanaman dapat diberikan ZPT dengan kondisi tertentu agar mendapat pertumbuhan yang optimum. Kandungan auksin yang lebih rendah dibandingkan dengan sitokinin dapat mempercepat pembentukkan tunas melalui inisiasi pembentukkan sel, dan merangsang perkembangan pucuk tunas menurut Buchory dan Karjadi (2008), sehingga pemberian sitokinin melalui perlakuan dapat meningkatkan kandungan sitokinin tanaman dan memaksimalkan pertumbuhan tunas. Beberapa penelitian yang telah dilakukan membuktikan bahwa pemberian sitokinin mampu meningkatkan pertumbuhan tunas suatu tanaman. 
Perlakuan pemberian air kelapa sebesar $200 \mathrm{ml}$ pada penelitian yang dilakukan oleh Darlina (2016) menunjukkan peningkatan jumlah tunas terbaik. Penelitian lainnya yang dilakukan oleh Astutik (2008) menyatakan bahwa penggunaan air kelapa 7,5\% dan $15 \%$ memberikan pengaruh terbaik pada pembentukan tunas pisang. Penelitian mengenai penggunaan ZPT berupa BAP oleh Siswiarti (2002) menunjukkan bahwa penggunaan BAP 60 ppm mampu mempercepat pembentukkan tunas dan meningkatkan jumlah tunas tanaman teh pada fase tanaman menghasilkan. Penelitian penggunaan BAP lainnya yang dilakukan oleh Saefas et al. (2017) menyatakan bahwa penggunaan BAP 60 pmm dan BAP 120 ppm memberikan hasil terbaik pada variabel jumlah tunas.

Tabel 2. Rataan rasio pertambahan jumlah tunas tanaman akibat pemberian zat pengatur tumbuh air kelapa dan BAP pada tanaman teh Klon GMB 7 setelah centering ke-2

\begin{tabular}{lcccccc}
\hline \multirow{2}{*}{ Perlakuan } & \multicolumn{5}{c}{ Pertambahan Panjang Tunas (cm) } \\
\cline { 2 - 7 } & 2 MSP & 4 MSP & 6 MSP & 8 MSP & 10 MSP & 12 MSP \\
\hline A (Kontrol) & 0,02 & 0,03 & 1,17 & 1,42 a & 0,64 & 0,05 \\
B (Air kelapa 25\%) & 0,04 & 0,40 & 0,82 & $1,98 \mathrm{ab}$ & 0,29 & 0,22 \\
C (Air kelapa 50\%) & 0,00 & 0,41 & 1,36 & $3,63 \mathrm{c}$ & 1,22 & 0,14 \\
D (Air kelapa 75\%) & 0,18 & 0,13 & 1,14 & $2,59 \mathrm{abc}$ & 1,02 & 0,09 \\
E (BAP 60 ppm) & 0,06 & 0,22 & 0,83 & $1,86 \mathrm{ab}$ & 0,74 & 0,16 \\
F (BAP 90 ppm) & 0,01 & 0,21 & 0,41 & $2,45 \mathrm{abc}$ & 1,58 & 0,24 \\
G (BAP 120 ppm) & 0,06 & 0,05 & 0,94 & $3,44 \mathrm{bc}$ & 0,76 & 0,21 \\
\hline
\end{tabular}

Keterangan : 1). MSP = Minggu Setelah Perlakuan.

2). Angka yang tidak diiringi dengan notasi pada kolom yang sama menunjukkan tidak adanya perbedaan nyata pada taraf kepercayaan $5 \%$.

3). Angka yang diiringi dengan notasi pada kolom yang sama menunjukkan adanya perbedaan nyata pada taraf kepercayaan $5 \%$.

Pembentukan tunas baru terus meningkat pasca dilakukannya centering ke2 dan mencapai puncaknya pada 8 MSP. Perbedaan yang nyata pada 8 MSP diakibatkan oleh terjadinya akumulasi hormon sitokinin akibat pemberian ZPT secara berkala, sehingga mengakibatkan kandungan hormon sitokinin menjadi lebih tinggi dibandingkan dengan auksinnya. Pemberian ZPT sitokinin tersebut bahkan mampu meningkatkan rasio pertambahan jumlah tunas dari 6 MSP ke 8 MSP hingga 6 kali lipat lebih banyak (pada perlakuan F dari 0,12 menjadi 0,83 ).

Berdasarkan hasil analisis air kelapa yang digunakan dalam percobaan, total kandungan sitokinin termasuk di dalamnya kinetin dan zeatin lebih banyak dibandingkan dengan total kandungan auksin (GA3 dan IAA) sehingga mendukung pembentukan tunas pada tanaman teh. Pemberian air kelapa $50 \%$ pada perlakuan $\mathrm{C}$ efektif diserap tanaman karena tidak terlalu pekat dan memiliki kandungan sitokinin yang lebih 
banyak dibanding penggunaan air kelapa $25 \%$ pada perlakuan B sehingga memberikan hasil yang optimal.

Kondisi pertambahan dan pengurangan rasio jumlah daun pada Tabel 1 yang menunjukkan bahwa perlakuan $\mathrm{C}$ memberi pengaruh nyata yang lebih baik dibandingkan perlakuan A pada 4 MSP juga berperan dalam rasio pertambahan jumlah tunas. Perlakuan $\mathrm{C}$ yang mampu mempertahankan daunnya dan membentuk daun baru memiliki daun lebih banyak sehingga dapat memberikan lebih banyak energi melalui fotosintesis untuk membentuk tunas baru dengan lebih baik.

Pembentukan tunas yang telah mencapai puncaknya pada 8 MSP akan mengalami penurunan setelahnya, karena pertumbuhan tanaman terfokus pada pertumbuhan dan perkembangan bagian tanaman lainnya seperti perbesaran ukuran diameter cabang dan tunas yang masih merupakan salah satu fungsi sitokinin yaitu pembelahan sel. Tunas-tunas yang telah tumbuh juga menyebabkan kembali terbentuknya sintesis auksin pada bagian ujung tunas, peningkatan hormon auksin pada tanaman tersebut dapat menekan sintesis sitokinin (Darmanti et al., 2008). Kondisi yang demikian dapat menyebabkan terjadinya keseimbangan antara auksin dan sitokinin yang dapat mengakibatkan terjadinya keseimbangan dalam pertumbuhan tunas, akar, dan daun (Kurniati et al., 2017).

\section{Pengamatan Penunjang}

Berdasarkan data hasil penelitian, perbedaan nyata baru terlihat sejak 8 MSP. Hal tersebut kemungkinan disebabkan oleh adanya proses pemulihan (recovery) tanaman pasca centering ke-2, selain itu kondisi lahan yang termasuk kedalam dataran rendah mengakibatkan tingginya intensitas cahaya yang menyebabkan suhu menjadi cukup tinggi dan mengganggu pertumbuhan tanaman teh.

Menurut Effendi et al. (2010) suhu optimum yang mendukung pertumbuhan tanaman teh dengan baik berkisar antara 13$25^{\circ} \mathrm{C}$ dan pertumbuhan tanaman teh dapat terhambat bahkan berhenti apabila suhu mencapai $30^{\circ} \mathrm{C}$. Berdasarkan pengamatan yang dilakukan terhadap suhu, didapati suhu optimum yang mendekati bahkan mencapai $30^{\circ} \mathrm{C}$. Kondisi tersebut kemungkinan mempengaruhi pertumbuhan tanaman teh sehingga pertumbuhan tidak berjalan optimum.

Penanaman pohon pelindung dapat dilakukan untuk mengatasi tingginya suhu pada lahan tanaman teh yang ditanam di dataran rendah (Wibowo, 1997). Penanaman pohon pelindung pada tanaman teh klon GMB 7 dilakukan pada sekitar 4 MSP, dimana daun - daun pada pohon pelindung mulai tumbuh sekitar 5-6 MSP.

Pemberian pohon pelindung menunjukkan hasil yang positif terlihat dari tanaman teh yang mulai tumbuh subur dan berkurangnya pengguguran daun teh serta memberikan kondisi yang mendukung tanaman dalam membentuk tunas sehingga menghasilkan hasil yang berbeda nyata pada 8 MSP. Perbedaan nyata juga disebabkan oleh terakumulasinya kandungan sitokinin pada tanaman akibat pemberian ZPT sehingga merangsang pembentukan tunas.

Zat pengatur tumbuh BAP memiliki kandungan sitokinin sehingga dapat merangsang pembentukkan tunas. Air kelapa 
muda yang digunakan juga mengandung sitokinin berdasarkan analisis yang telah dilakukan di Laboratorium Badan Penelitian dan Pengembahang Pertanian pada 2017. Hasil analisis air kelapa menunjukkan adanya kandungan berbagai hormon seperti $\mathrm{Ca}$, auksin, dan sitokinin. Total kandungan hormon sitokinin berjumlah $0,008 \%$ dan hormon auksin berjumlah $0,0057 \%$. Kondisi tersebut menunjukkan bahwa kandungan hormon sitokinin lebih tinggi dibandingkan dengan hormon auksin, sehingga dapat merangsang pembentukkan tunas.

\section{SIMPULAN}

Pemberian perlakuan air kelapa 50\% mampu menunjukkan pengaruh positif terhadap rasio pertambahan dan pengurangan jumlah daun (daun/cabang) pada 2 MSP dan 4 MSP serta rasio pertambahan jumlah tunas (tunas/cabang) pada 8 MSP. Pemberian air kelapa 50\% mampu mempertahankan dan menambah jumlah daun hingga 0,26 daun/cabang pada 2 MSP dan 0,24 daun/cabang pada $4 \mathrm{MSP}$, serta menambah jumlah tunas sebesar 1,53 tunas/cabang pada $8 \mathrm{MSP}$.

\section{DAFTAR PUSTAKA}

Astutik, 2008. Penggunaan air kelapa dalam media kultur jaringan pisang. Buana sains 8, 67-72.

Buchory, A.K.A., Karjadi, A.K., 2008. Pengaruh Auksin dan Sitokinin terhadap Pertumbuhan dan Perkembangan Jaringan Meristem Kentang Kultivar Granola. Jurnal Hortikultura 18, 380-384.

Darlina, 2016. Pengaruh penyiraman air kelapa (Cocos nucifera L.) terhadap pertumbuhan vegetatif lada (Piper ningrum L.). Jurnal Ilm. Mhs.
Pendidik. Biol. 1, 20-28.

Darmanti, S., Nintya, S., dan Tanti, D.R., 2008. Perlakuan defoliasi untuk meningkatkan pembentukan dan pertumbuhan cabang lateral jarak pagar (Jatropha curcas). Jurnal Anat. 16, 13-20.

Djamhuri, E., 2011. Pemanfaatan Air Kelapa untuk Meningkatkan Pertumbuhan Stek Pucuk Meranti Tembaga ( Shorea leprosula Miq .). Jurnal Silvikultur Trop. 2, 5-8.

Effendi, D.S., Syakir, M., Yusron, M., dan Wiratno, 2010. Budidaya dan Pasca Panen Teh. Pusat Penelitian dan Pengembangan Perkebunan, Bogor.

Fahmi, Z.I., 2016. Kajian pengaruh pemberian sitokinin terhadap pertumbuhan tanaman. Balai Besar Perbenihan dan Proteksi Tanaman Perkebunan Surabaya.

Haq, M.S., Karyudi, 2013. peningkatan produksi teh melalui penerapan kultur teknis. Jurnal War. PPTK 24, 71-84.

Hardjo, H., 2014. Statistik Teh Indonesia (Indonesian Tea Statistics) 2014. Badan Pusat Statistik Republik Indonesia, Jakarta.

Hendaryono, S., dan Wijayani, A., 1994. Teknik Kultur Jaringan. Kanisius, Yogyakarta.

Kurniati, F., Sudartini, T., dan Hidayat, D., 2017. Aplikasi Berbagai ZPT Alami untuk Meningkatkan Pertumbuhan Bibit Kemiri Sunan (Reutealis trisperma (Blanco) Airy Shaw). Jurnal Agro IV, 40-49.

Leovici, H., KKastono, D., Putra, dan E.T.S., 2014. Pengaruh Macam dan Konsentrasi Bahan Organik Sumber Zat Pengatur Tumbuh Alami terhadap Pertumbuhan Awal Tebu (Saccharum officinarum L.). Jurnal Vegetalika 3, 22-34.

Lestari, E., Nurhidayati, T., dan Nurfadhilah, S., 2013. Pengaruh Konsentrasi ZPT 
2,4-D dan BAP terhadap Pertumbuhan dan Perkembangan Biji Dendrobium laxiflorum J.J Smith secara In Vitro. Jurnal Sains dan Seni Pomits 2, 4347.

Listiawati, A., and Mulyani, S.R.I., 2010. The effect of coconut water and naphthalene acetic acid (NAA) application on the in vitro growth of Paraphalaeonopsis serpentilingua from West Kalimantan. Journal of Nusant. Biosci. 2, 62-66.

Saefas, S.A., Rosniawaty, S., dan Maxiselly, Y., 2017. Pengaruh konsentrasi zat pengatur tumbuh alami dan sintetik terhadap pertumbuhan tanaman teh (Camellia sinensis (L.) O . Kuntze) klon GMB 7 setelah centering. Jurnal Kultivasi. 16, 368-372.

Setyamidjaja, D., 2000. Teh: Budidaya dan Pengolahan Pacsa Panen, edisi ke6. Kanisius, Yogyakarta.

Siswiarti, H., 2002. Pengaruh Berbagai Konsentrasi Dan Frekuensi Pemberian Zat Pengatur Tumbuh (Sitokinin Dan Adenin) Terhadap Pemecahan Pucuk Tanaman Teh Produksi (Camellia sinensis L.). Tesis. Sumatera Utara.

Wibowo, Z.S., 1997. Petunjuk Kultur Teknis Tanaman Teh, edisi ke-2. Pusat Penelitian Teh dan Kina, Bandung.

Yong, J.W.H., Ge, L., Ng, Y.F., dan Tan, S.N., 2009. The chemical composition and biological properties of coconut (Cocos Nucifera L.) water. Journal of Molecules 14, 5144-5164. 